\title{
Execution of the Occupational Safety and Health Act (1994) in the Construction Industry from Contractors' Point of View
}

\author{
H. Awang ${ }^{1, a}$, I.M. Kamil ${ }^{2}$ \\ ${ }^{1,2}$ School of Housing, Building and Planning, Universiti Sains Malaysia, 11800, Penang, Malaysia
}

\begin{abstract}
Construction is one of the highest contributing industries to occupational accidents by sector in Malaysia. Statistics have been drawn from year to year that show an increasing number of cases of accidents by industry sector. While it is impossible to completely eliminate all accidents, with a proper and effective safety and health policy or rules set by top management, especially contractors, the rate of accidents on construction sites can be reduced. The main objective of this study is to analyse the degree of application of the Occupational Safety and Health Act 1994 (OSHA 1994) in the construction industry and to identify the contributing factors leading to a lack of execution of OSHA 1994 on construction sites with a primary focus on contractors' point of view. Five on-going construction projects in Perak were selected as case studies and site inspections were conducted. The results showed that none of the contractors have fully implemented the rules and regulations provided by the government. Within this report, some recommendations are made towards enhancing the safety and health issues on construction sites.
\end{abstract}

\section{Introduction}

The Occupational Safety and Health Act 1994 (OSHA) involved a huge movement and transformation from year to year and was well-established in February 1994 in Malaysia. The main function and purpose of OSHA is to encourage employers and employees to create effective safety and health measures at the workplace. In the construction industry, OSHA is important as it provides a safety and health policy that must be defined and recognized by both parties, that is, the employers and the workers. Overall, employers such as contractors have a duty to make sure the construction site is safe and free from health hazards as well as to follow any rules and regulations outlined in the act. Contractors are liable to follow reasonable steps to ensure safety plans are detailed and correctly implemented until the construction work is done, to provide a plan and arrangements to make sure only authorized persons can enter the construction area, to display particular details about harmful substances as well as safety signs that can be read by the workers, and to give reasonable instructions to the sub-contractor and workers which includes rules in the safety plan when necessary[1].

Accidents on construction sites are often caused by factors that may come from a lack of organizational commitment, uncontrolled operations, lack of safety regulations, personal protective equipment and training, poor technical supervision and unsafe equipment [2]. Some initiatives have been made by the Malaysian government to reduce the number of cases of occupational accidents in

${ }^{a}$ Corresponding author : hanizam@usm.my 
the construction industry. Initiatives such as the establishment of the Department of Occupational Safety and Health (DOSH), the Construction Industry Development Board (CIDB) and the National Institute of Occupational Safety and Health (NIOSH) show that the government is very determined to reduce the statistics of the number of accidents on construction sites.

Contractors take a major share of the responsibility on construction sites as their work deals with the management of the overall project. They must show a good attitude towards safety management and come up with initiatives to reduce the rate of accidents that happen at the workplace [3]. Unsafe behaviour of workers is the most significant factor causing site accidents, and $90 \%$ of such accidents actually lead to death. However, $70 \%$ of construction accidents can be prevented by positive action from management [4]. From the data collected, it can be concluded that contractors do not fully implement the safety rules and regulations that are established by the government. With the establishment of various acts and guidelines such as OSHA 1994, CIDB, NIOSH and DOSH, contractors should take responsibility to make initiatives and implement the existing safety rules and regulations at their construction sites. Contractors have the highest level of influence on site safety because they monitor, coordinate and direct the work of the workers [5]. Hence, this paper's aim is to investigate the degree to which OSHA 1994 has actually been applied among contractors in the construction industry in Malaysia.

\section{Methodology}

Five construction sites were chosen as case studies. The selected construction sites are located at Perak Darul Ridzuan. The sites chosen represent both small and large tendering capacity, that is, contractor grade 3 and grade 7. A set of questionnaires consisting of twelve questions was prepared and used for interview sessions with the respondents. There were five respondents, all of whom are contractors already registered with the Construction Industry Development Board (CIDB). A site inspection was conducted in order to identify the current situation of each selected construction site.

\section{Results and Discussion}

Table 1 below shows the results from the data collected and site inspections of the five case studies of on-going projects in Perak.

Table 1. Results of interview sessions with the contractors of the five on-going construction projects in Perak

\begin{tabular}{|c|c|c|c|c|c|}
\hline $\begin{array}{ll}\text { Question } & \text { Respondent } \\
\end{array}$ & 1 & 2 & 3 & 4 & 5 \\
\hline 1. OSHA 1994 Exposure. & $\checkmark$ & $\checkmark$ & $\checkmark$ & $\checkmark$ & $\checkmark$ \\
\hline 2. Personal Protective Equipment [PPE]. & $\mathrm{X}$ & $\checkmark$ & $\checkmark$ & $\mathrm{X}$ & $\mathrm{x}$ \\
\hline 3. Safety measures law on worker. & $\begin{array}{c}\text { OSHA } \\
1994, \\
\text { CIDB }\end{array}$ & $\begin{array}{c}\text { OSHA } \\
1994, \\
\text { CIDB }\end{array}$ & $\begin{array}{c}\text { OSHA } \\
1994, \\
\text { CIDB }\end{array}$ & $\begin{array}{c}\text { OSHA } \\
1994, \\
\text { CIDB }\end{array}$ & $\begin{array}{c}\text { OSHA } \\
1994, \\
\text { CIDB }\end{array}$ \\
\hline 4. Penalties and compound. & $\mathrm{X}$ & $\mathrm{X}$ & $\checkmark$ & $\mathrm{x}$ & $\checkmark$ \\
\hline 5. Safety and hazard information on site. & $\mathrm{x}$ & $\mathrm{x}$ & $\checkmark$ & $\mathrm{x}$ & $\checkmark$ \\
\hline 6. Entry limitations for public to the site. & $\checkmark$ & $\checkmark$ & $\checkmark$ & $\checkmark$ & $\checkmark$ \\
\hline $\begin{array}{l}\text { 7. Safety field manual and Personal Protective } \\
\text { Equipment (PPE) Policy. }\end{array}$ & $\mathrm{x}$ & $\mathrm{x}$ & $\mathrm{x}$ & $\mathrm{x}$ & $\mathrm{x}$ \\
\hline 8. Workers welfare. & $\checkmark$ & $\checkmark$ & $\checkmark$ & $\checkmark$ & $\checkmark$ \\
\hline 9. Instruction and information & $\mathrm{x}$ & $\mathrm{x}$ & $\checkmark$ & $\mathrm{x}$ & $\checkmark$ \\
\hline $\begin{array}{l}\text { 10. Monitoring activities on implementation of } \\
\text { laws and site environment control. }\end{array}$ & $\mathrm{x}$ & $\mathrm{x}$ & $\checkmark$ & $\mathrm{x}$ & $\checkmark$ \\
\hline 11. Site safety officer. & $\mathrm{x}$ & $\mathrm{x}$ & $\mathrm{x}$ & $\mathrm{x}$ & $\mathrm{x}$ \\
\hline $\begin{array}{l}\text { 12. Security procedures on site for access of } \\
\text { public and other person than workers. }\end{array}$ & $\mathrm{x}$ & $\mathrm{x}$ & $\checkmark$ & $\mathrm{x}$ & $\checkmark$ \\
\hline
\end{tabular}


For this study, the list of questions used in the interview sessions with the contractors was related to the guidelines that are listed in Part IV of OSHA 1994. From the data collected, it can be concluded that $100 \%$ of the respondents agreed that they were aware of and know about the existence of OSHA 1994. Apart from OSHA 1994, the respondents also noted other rules and guidelines such as the Construction Industry Board Malaysia (CIDB) and the National Institute of Occupational Safety and Health (NIOSH). Other that OSHA 1994 exposure, all observed construction sites were found to be $100 \%$ compliant with rules requiring the contractor to provide welfare for the workers as well as entry limitations for the public to the construction site (Figure 1). Welfare can be defined as amenities for the convenience of the workers, such as housing, water and electricity (Figure 2). Meanwhile, all the construction sites provided zinc fences for safety as entry limitations to stop the public from entering the construction site.

The results show that $60 \%$ of the contractors claimed their workers were provided with personal protective equipment (PPE) such as safety helmets and boots, but that it was up to the workers whether to wear them or not. However, during the site inspection, most of the workers did not wear the protective safety equipment and the contractors were not very proactive about it (Figure 3 ). The other $40 \%$ proved to be very strict in the implementation of PPE for the workers due to a few reasons: because of safety factors and because it is a regulation that must be complied with at all construction sites (Figure 4).

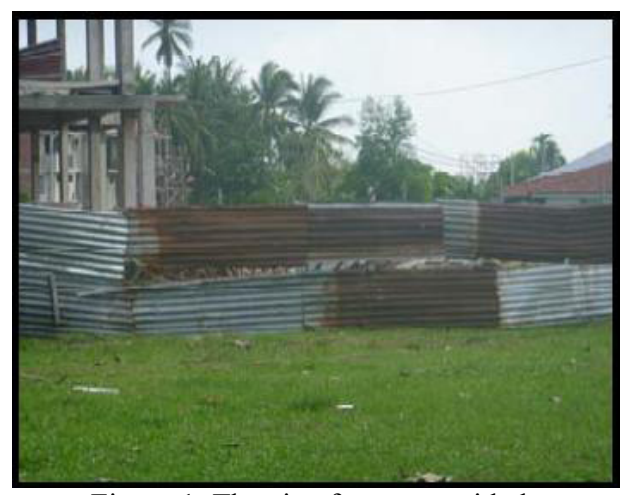

Figure 1. The zinc fences provided as entry limitations at the construction site

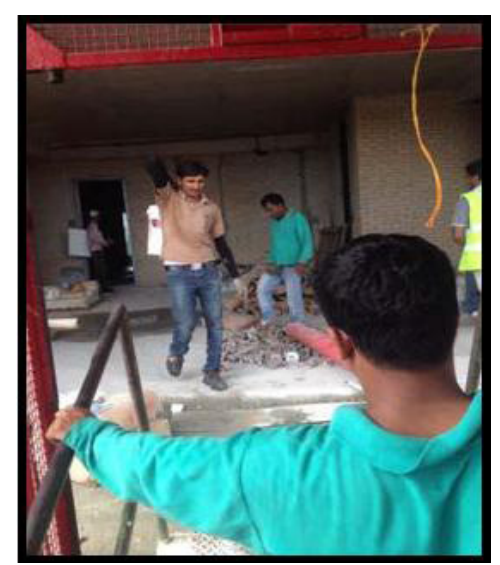

Figure 3. Workers not wearing any (PPE) during construction work.

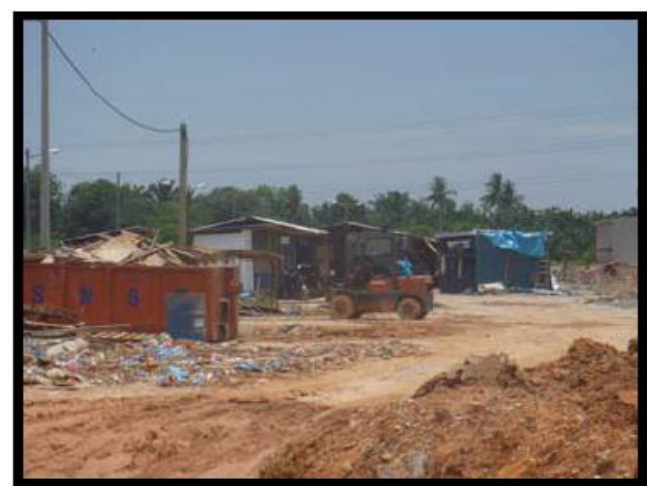

Figure 2 A look at welfare and amenities at the construction site in terms of housing

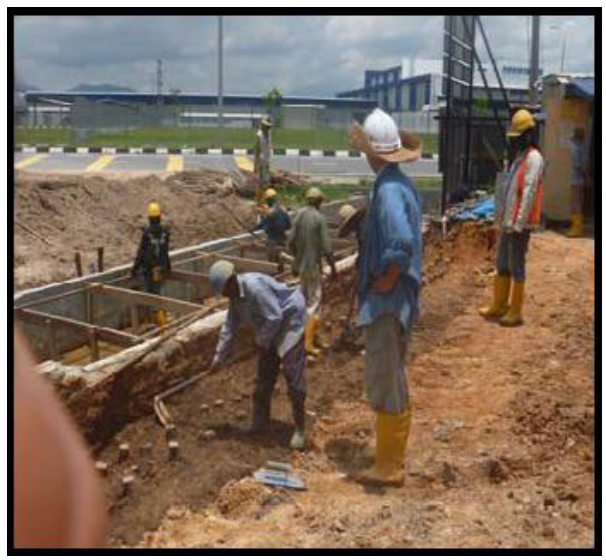

Figure 4. Workers are wearing PPE and following the rules and regulations

Part IV of the act addresses obligations to charge penalties or fines to contractors who disobey the rules, for example, not requiring the workers to wear PPE during construction work, and also not 
providing any written safety and health policy statement for their crew. $60 \%$ of those questioned claimed that they were aware of this issue but do not take it seriously. The reasoning given by the respondents was that they find it unnecessary and because of financial problems. The other $40 \%$ take this matter seriously because they want to make sure the site is safe from any hazard and to avoid problems with authorities in the future.

Safety and hazard information should be provided at every construction site. From the data collected, $60 \%$ of those questioned claimed that they provide information on matters of site hazards but it does not meet the set standards (Figure 6 and Figure 7). Rather, only basic information is provided. The remaining $40 \%$ do not provide any safety and hazard information on the construction site (Figure 5).

Instructions and information can be presented at a toolbox meeting, where all the workers are given guidelines about their work and other requirements that must be followed by the workers such as possessing a compulsory CIDB Green Card. $60 \%$ of those questioned felt that it was unnecessary to hold toolbox meetings due to the type of construction work being done and due to the contractors' confidence in the ability of the workers to perform their duties even without any instruction. Another $40 \%$ do hold toolbox meetings on their site. (Figure 8 )

The monitoring of rule implementation and site environment control should be entrusted to the site safety officer. However, $100 \%$ of the findings showed that at none of the construction sites had any safety officer been established as part of the site management. However, $40 \%$ out of that $100 \%$ claimed that the implementation of site rules and site environment control were monitored, but this was done under the direction of the supervisor and not the safety officer.

Lastly, in terms of on-site security procedures for public access and persons other than workers, $40 \%$ of the sites studied provided security guards for safety purposes. This was to avoid the construction site from public intrusion and to avoid accidents from occurring. There were also some procedures before entering the site, such as requiring visitors to make an appointment and wear appropriate attire before entering the site.

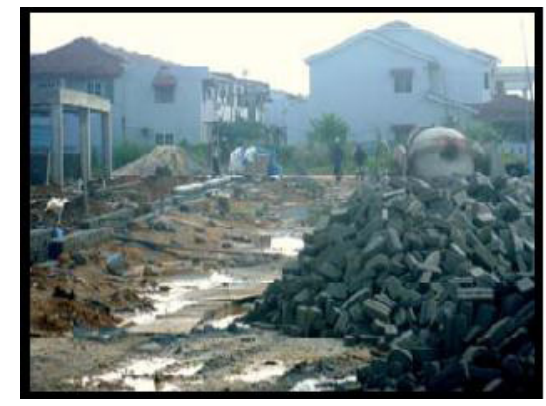

Figure 5 . The condition of a site where no safety and hazard information has been provided

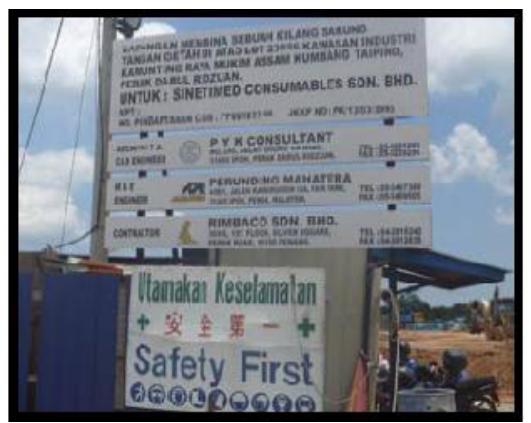

Figure 7. Construction information and hazard warnings Figure 8. Toolbox meeting notice at a construction site

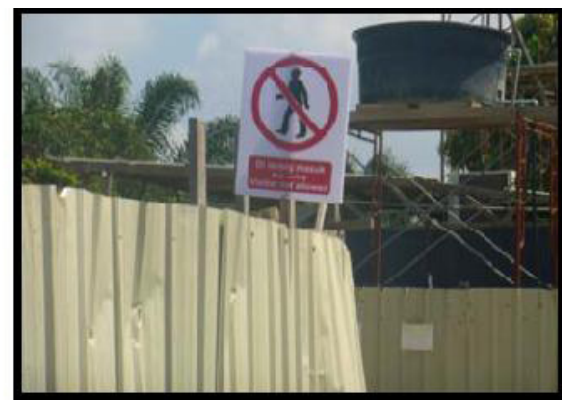

Figure 6. Safety information for the public

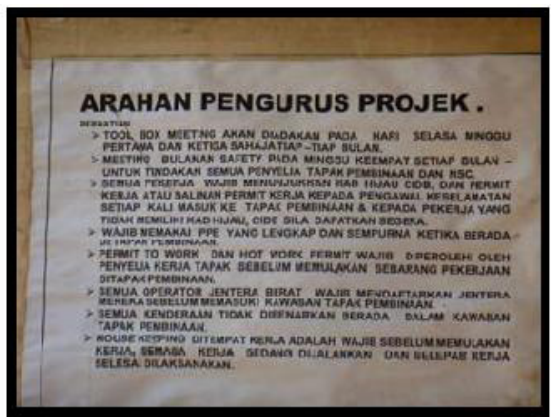




\section{Factors That Influence the Execution of Site Safety on Construction Sites}

From the data collected, some analysis and discussion have been made on factors that influence the implementation of site safety on the construction sites. The most significant factors that can be singled out are the top management system, failure of the work system, safety attitudes and failure of policy enforcement.

\subsection{Top Management System}

The top management system plays an important role in the implementation of site safety on construction sites. Management that usually involves planning and controlling project strategies should be designated to those in top positions such as contractors, instead of the workers who are not normally aware of all the constraints that may exist on the construction site. Good top management practices have a positive impact on overall project safety [6]. Management should make active decisions towards ensuring the site's and workers' safety, and not give this task to third parties. Overall, third parties, which consist of the workers, should be excluded from risk during construction work [1].

\subsection{Failure of Work Systems}

Work system failure is also one of the factors that influence the implementation of safety and health on construction sites. Safety objectives can be achieved with an excellent system of work which includes clear work instructions, adequate training and serious recognition of hazards on the site. The most common responses from contractors to the question of failure of the safety system that can be concluded from this research are: limitation of resources (workers), industry tradition, lack of technical competence, lack of authority, lack of information, full reliance upon the workers to take care of their own safety instead of the management taking responsibility, and the management's emphasis on performance over safety.

Another example of risk assessment is to adapt work to the individual, giving them each control over the speed of work where possible, rather than making the individual adjust to the work, making sure the workers know what they need to do to remain safe and healthy, as well as giving priority to solutions that protect the whole workplace rather than individuals [1].

\subsection{Failure of Policy Enforcement}

Policy enforcement failure may be due to contractors who do not implement site safety rules and guidelines established by the government or formulated by their own company. Contractors consider whether or not to establish a site safety officer based on the notion that the cost of safety is paid by the organization, either through the uncontrolled cost of accidents or through the controlled cost of a safety program [7]. It should be noted that, without rules and regulations on the construction site that can be used as guidelines, especially among the workers, an uncontrolled cost of accidents can result. This may include loss of productivity, administrative time for investigations, disruption of the schedule, wages paid to the injured workers, adverse publicity, liability claims and equipment damage [7]. Policy enforcement failure can be avoided by adopting it as normal organizational culture in the company's management system. Health and safety policies should be established by every construction firm's top management, regardless of the grade of contractor.

\subsection{Safety Attitudes}

Last but not least, safety attitudes should not only apply to employers, but also to the workers. In regard to employers, contractors should have the responsibility to make sure that the construction 
under progress is safe and follows the rules and guidelines provided by the government. The workers should cooperate together with the management in determining whether individuals on site engage in safe practices.

\section{Conclusion}

The construction industry is highly vulnerable to all sorts of accidents and hazards cause by numerous factors. With the implantation and enforcement of appropriate regulations by the government, statistics in the number of accidents and deaths among construction workers can be reduced. In brief, all parties such as the employers, and especially contractors and workers, should be involved in preventing risk and working together in order to mitigate the occurrence of accidents. Therefore, appropriate recommendations for enhancing safety and health in construction should be carried out and should be adopted, especially by contractors, in order to create a safer workplace environment.

\section{References}

1. Allan, J. H., 2005, Principles of Construction Safety: Techniques of Construction Safety Management. $2^{\text {nd }}$ Edition, Cornwall: MPG Books Ltd, Blackwell Publishing, London. Publishing

2. Tam, C.M., Zeng, S. N., and Deng, Z.M., 2004, Identifying Elements of Poor Construction Safety Management in China. Safety Science.

3. Sioe, M. S., 2013, Contractors Attitude towards Enhancing Safety Performance of Construction Firms In Penang, Universiti Sains Malaysia.

4. De-Chun, N., Wang, J. P., and Ni, G. D., 2010, Analysis of Factor Affecting Safety Management in Construction Project, International Conference on Management and Service Science (MASS) China University of Min. and Techl., Xuzhou, China 24-26 ${ }^{\text {th }}: 1-5$

5. O' Toole, M., 2002, The Relationship Between Employees: Perception of Safety and Organizational Culture, Journal of Safety Research, 33 (1): 231-243

6. Wilson Jr, J. M., and Koehn, E.,2000, Safety Management Problems Encountered and Recommended Solution, Journal of Construction Engineering and Management, 126 (2): 77-79

7. Koehn, E. E., Kothari, R. K., and Pan, C.S., 1995, Safety in Developing Countries: Professionals and Bureaucratic Problems, Journal of Construction Engineering and Management, 121(3): 261265 